\title{
Competitividade Organizacional: uma Tentativa de Reconstrução Analítica
}

\section{Organizational Competitiveness: an Attempt of Analytical Reconstruction}

Clóvis L. Machado-da-Silva

Ph.D. em Estudos Organizacionais e Estratégia pela Michigan State University, EUA. Professor Titular do CEPPAD/UFPR e Professor do PMDA/UP, Curitiba/PR, Brasil.

Valéria Silva da Fonseca*

Doutora em Engenharia de Produção pela UFSC. Professora Adjunta do PPAD/PUCPR, Curitiba/PR, Brasil.

* Endereço: Valéria Silva da Fonseca

Pontifícia Universidade Católica do Paraná, Escola de Negócios, Programa de PósGraduação em Administração, Rua Imaculada Conceição, 1155, Bloco Acadêmico, $1^{\circ}$ andar, Prado Velho, Curitiba/PR, 80215-901.E-mail: vsf29@hotmail.com

Este artigo foi originalmente publicado na Organizações \& Sociedade, v. 4, n. 7, Dezembro, 1996, pp. 97-114. 


\title{
ResUMO
}

Neste final de século, o processo de globalização dos mercados e seu efeito sobre os padrões de conduta econômica, política, social e organizacional, vêm assumindo importância crescente, compondo um cenário no qual a competitividade emerge como uma questão imperativa. Em decorrência, intensificam-se na literatura especializada as discussões em torno da necessidade de elaboração de um conceito de competitividade mais claro e abrangente, que transcenda a tendência existente no campo da microeconomia de associá-la somente à indicadores de desempenho ou de eficiência técnica. Para tanto, economistas menos ortodoxos têm sugerido vinculações a fatores como estratégia e padrões de concorrências setoriais, estudiosos organizacionais têm enfatizado mecanismos de seleção e de exclusão competitiva, pressupondo a relevância de se considerar a influência das circunstâncias ambientais. No entanto, na essência tais abordagens ainda se concentram na avaliação da eficiência de aspectos organizacionais. Acredita-se que o problema reside no fato de ambas confinarem o seu tratamento do ambiente aos limites do mercado ou de uma população de organizações, menosprezando a força das pressões que os rodeiam. Esse é foco de análise da teoria institucional. Portanto, pretende-se apresentar no presente artigo alguns pressupostos da teoria microeconômica e da teoria institucional, e demonstrar seu potencial de interseção e de consequente aplicação ao exame mais apurado do fenômeno da competitividade.

Palavras-chave: competitividade organizacional; teoria microeconômica; teoria institucional.

\begin{abstract}
At the end of this century, the market globalization process and its effects over the economic political, social and organizational standards have been assuming an increasing importance, making up scenery where competition emerges like an imperative question. Due to this, discussions about the necessity of creating a more comprehensive and clearer concept of competition that surpasses the existing tendency in the microeconomic field of associating it only with performance indicators of technical efficiency have been intensified in the specialized literature. Therefore, less orthodox economists have suggested some link with factors like strategy and sectoral competition standards. Besides, organizational scholars have emphasized mechanism of choice and of competitive exclusion, assuming the importance of considering the influence of surrounding circumstances. Nevertheless, those considerations still concentrate on the evaluation of the effectiveness of organizational aspects. It's assumed that the problem is related to the fact that both border up their environment treatment to market limits or to an organizational population, underestimating the power of the surrounding pressure. This is the focus of analysis of the institutional theory. We also want to demonstrate their intersection potential and the consequent application on the more refined exam of the competitive phenomenon.
\end{abstract}

Key words: organizational competitiveness; microeconomic theory; institutional theory. 


\section{INTRODUÇÃO}

Neste final de século, o mundo vive um momento singular. Como afirma Senge (1990), pela primeira vez na história a humanidade está habilitada a gerar mais informação do que pode absorver, mais interdependência do que pode gerenciar, mais transformações do que pode acompanhar. O resultado é a explosão de um acelerado processo de globalização, com amplas repercussões nos padrões de conduta política, econômica, social e organizacional estabelecidos após à Revolução Industrial. Por conta da contenção orçamentária, o Estado perde a sua capacidade de fornecer subsídios e empréstimos, de investir em infra-estrutura e de controlar o consumo. Fronteiras nacionais desaparecem e blocos regionais de comércio emergem então, possibilitando às grandes corporações mundiais assumir o poder sobre a determinação, produção e distribuição de bens e serviços públicos e privados. E as organizações obrigam-se à cortar custos, elevar os níveis de automação e ajustar os sistemas gerenciais, dentre outras medidas, a fim de enfrentar a acirrada disputa com os concorrentes internacionais (Nascimento, 1996). Tal situação remete à necessidade de reavaliação do conceito de competitividade.

De acordo com Kupfer (1991), apesar da frequente discussão em torno do tema registrada na literatura especializada, a definição de competitividade carece de maior clareza e exatidão devido a tendência em associá-la, na tradição do enfoque microeconômico, a indicadores de desempenho ou de eficiência técnica. À procura de um enfoque alternativo, o autor observa que tais abordagens pecam por restringirem-se aos aspectos correntes das organizações e dos produtos que fabricam. Desconsidera-se o processo de escolha de estratégias empresariais em um contexto dinâmico, regido por uma situação concorrencial e pela interação entre as estruturas que o condicionam e as condutas inovadoras das organizações que podem transformá-lo. Nesse sentido, torna-se imperativo criar um conceito de competitividade que abarque noções de tempo e de expectativas, e que permita mensurá-la como um fator de ajuste às circunstâncias ambientais.

Dentre os estudos organizacionais orientados por tal prerrogativa, destacamse aqueles fundamentados na abordagem da ecologia populacional. Sob esta perspectiva, a competitividade é vista como um tipo de relação permeada pela disputa entre organizações, ou populações de organizações, por recursos escassos mas essenciais a sua sobrevivência. Nesse caso, o sucesso ou fracasso de uma organização depende da sua habilidade em atingir uma vantagem competitiva perante à condições de similaridade de requerimento dos recursos, de densidade 
e de diversidade organizacional em termos de produtos, serviços e padrões de consumo. Em analogia aos mecanismos biológicos, isso decorre da concepção de que duas espécies que habitam um mesmo nicho possuem dificuldade em conviver em equilíbrio, uma vez que lutam por recursos similares. As organizações sujeitam-se, assim, à processos de seleção e de exclusão competitiva, o que estimula a busca de novos métodos de fabricação e de gestão, de arranjos estruturais cada vez mais eficientes (Hannan \& Freeman, 1977, 1989).

Ao examinar-se atentamente os quadros de referência acima expostos, verificase que a noção de competitividade ainda parece encerrar as características intrínsecas à organização, o que pouco contribui para a sua elucidação à luz dos atuais desafios a que se expõem as organizações. Conforme salientado, os adeptos da corrente ecológica têm enfatizado os processos externos de seleção e exclusão, e economistas menos ortodoxos têm sugerido vinculações a fatores como estratégia e padrões de concorrência. No entanto, na essência tais abordagens concentram-se na avaliação da eficiência de aspectos organizacionais, guardando resquícios de antigas concepções mecanicistas que tampouco a crescente adoção de visões evolucionistas parece haver conseguido suprimir. Acredita-se que o problema reside no fato de ambas confinarem o seu tratamento do ambiente aos limites do mercado ou de uma população de organizações, menosprezando a força das pressões que os rodeiam. A abordagem institucional tenta transpor o foco para essa direção, ao privilegiar a influência de elementos culturais socialmente construídos no estabelecimento das relações competitivas que aí se desenrolam.

Sem a pretensão de desenvolver conceitos e modelos, pretende-se apresentar no presente artigo alguns pressupostos da teoria microeconômica e da teoria institucional, e apenas demonstrar o seu potencial de interseção e de consequente aplicação à análise do fenômeno da competitividade. A utilidade de tal empreendimento encontra-se na necessidade de aprofundar a compreensão da temática em questão, sobretudo em países de industrialização recente nos quais se identifica, a exemplo do Brasil, a ocorrência de sérios problemas conjunturais que emperram a sua mobilização para o alcance de um melhor posicionamento competitivo na esfera global.

\section{Competitividade Sob Forma de Padrões Concorrenciais}

A idéia de competitividade implicitamente supõe conflito e rivalidade, o que dificulta a sua adequada apreensão. Em economia, ela pode ser abordada tanto no âmbito do Estado, representada na competitividade macroeconômica, como 
no âmbito organizacional, cerne da competitividade microeconômica. Quando se privilegia o plano micro, o tratamento recai sobre as características da organização ou de um produto, relacionadas à aspectos de desempenho ou de eficiência técnica dos processos produtivos e administrativos.

Com base no exame de diversos conceitos disponíveis na literatura especializada, Haguenauer (1983) verifica que, em linhas gerais, a competitividade como desempenho se expressa na posição alcançada pela organização no mercado em um dado momento, resultante da combinação de uma série de fatores como preço, qualidade, grau de diferenciação dos produtos, dentre outros. Nesse caso, a competitividade é guiada pela demanda, e o volume das exportações de uma organização ou de uma indústria no total do comércio internacional de um produto se inclui entre os seus principais indicadores.

A competitividade como eficiência é definida, por outro lado, pela habilidade da organização em fabricar produtos melhores do que seus concorrentes, de acordo com os limites impostos pela sua capacitação tecnológica, gerencial, financeira e comercial. Traduzida nas relações insumo-produto ou custo-preço, a competitividade é delimitada pelo produtor, e mensurável por indicadores como produtividade e técnicas de produção, em comparação àqueles apresentados pelas organizações de maior rendimento do setor.

A despeito da sua ampla utilização, autores como Kupfer (1991) destacam que estas abordagens não permitem captar o real fundamento da competitividade, por contemplá-la de maneira estática e atemporal. Participação no mercado, taxa de crescimento, lucratividade, dentre outros possíveis indicadores do desempenho de uma organização ou de uma indústria, configuram-se como consequências da competitividade e não como a sua origem. Do mesmo modo, qualquer indicador de eficiência toma-se relativo, à medida que parâmetros considerados importantes para a mensuração da competitividade tais como os melhores procedimentos praticados na indústria, são estabelecidos de acordo com o processo de busca e seleção desencadeado pelo mercado em um determinado momento, o que os inviabiliza enquanto base anterior de comparação. Em outras palavras, na vertente desempenho a competitividade constitui-se como um fenômeno ex-post e na vertente eficiência como um fenômeno ex-ante. Portanto, explicá-la apenas por tais variáveis, sobretudo pela versão do desempenho, pode levar à substituição do efeito pela causa.

Além disso, a restrição detectada imprime à questão um caráter tautológico: se a organização é competitiva por dominar o mercado, supõe-se que a dominação do mercado decorre da competitividade. Se a melhor técnica conduz à competitividade, a técnica mais competitiva se toma a melhor técnica, no conjunto daquelas utilizadas no mercado. Conforme Correa e Kupfer (1991), rejeitar a 
ocorrência dessa ambiguidade implica na redução da competitividade a um mero sinônimo de desempenho ou de eficiência, impossibilitando conferir ao conceito uma formulação teórica própria.

Para tanto, Kupfer (1991) propõe o desenvolvimento de um quadro referencial dinâmico, que inclua os aspectos mencionados, não que neles se esgote. Na realidade, o autor observa que desempenho e eficiência técnica igualmente decorrem de experiências acumuladas e das estratégias implantadas pela organização ao longo do tempo. Desse modo, o processo de escolha de estratégias competitivas atuais se desenrola a partir da avaliação do desempenho passado, além de expectativas incertas quanto à futuras variações contextuais.

Tendo em vista a necessidade de constante adaptação organizacional, a competitividade deve ser assim visualizada enquanto um fenômeno de natureza extrínseca, vinculado à situação concorrencial existente na indústria. Especificamente, enquanto "uma função da adequação das estratégias das empresas individuais ao padrão de concorrência vigente no mercado específico" (Kupfer, 1991, p. 25).

O padrão de concorrência é descrito como o conjunto de formas de concorrência prevalecentes em um espaço de competição, resultante da interação entre as forças concorrenciais que aí se revelam. As possíveis formas de concorrência incluem preço, qualidade, esforço de venda, diferenciação de produto, dentre outras, e as forças concorrenciais refletem as características estruturais do mercado e as condutas das organizações que nele atuam. Sob essa perspectiva, Kupfer (1991) considera que a competitividade é determinada pelo padrão de concorrência setorial.

Tal proposição tem demandado esforços de alguns estudiosos, no sentido de empreender pesquisas que confirmem a sua aplicabilidade. Correa e Kupfer (1991), por exemplo, buscam analisar os fatores que contribuíram para a formação dos padrões concorrenciais e, por conseguinte, para a competitividade da indústria brasileira de máquinas-ferramenta. Do mesmo modo, Campos e Ferraz (1992), atendo-se à trajetória de crescimento experimentada pelo complexo eletrônico durante os anos oitenta, procuram distinguir as tendências para o futuro por meio da identificação, ordenação e comparação dos principais componentes do padrão de concorrência em voga no início dos anos noventa com aqueles esperados para o seu final. Nesse sentido, os autores verificam que o produto, a oferta de mão-de-obra qualificada e as políticas públicas configuraram-se como elementos fundamentais para o estabelecimento das práticas concorrenciais no setor focalizado. E em termos de probabilidades, apontam o produto, o processo de 
produção, a oferta de mão-de-obra qualificada, as atividades de suporte à produção, a qualificação dos fornecedores, dentre outros, como os elementos passíveis de promover a consolidação de um novo padrão de concorrência. Vale ressaltar a expectativa já existente de acentuada diminuição da importância do Estado enquanto fonte de competitividade, corroborada pela literatura atual.

Subjacente aos resultados alcançados nas investigações apresentadas, emerge a questão relativa à maneira como as características estruturais de um mercado e as ações organizacionais interagem na consolidação ou na mudança do padrão de concorrência vigente em um dado espaço de competição. Para Kupfer (1991), as teorias microeconômicas convencionais também oferecem respostas pouco conclusivas a tal indagação, por limitarem-se a enfatizar uma ou outra dimensão. Portanto, de acordo com a sua proposição, a solução está na adoção de um enfoque interativo, no qual a postura estratégica das organizações seja vislumbrada como o motor básico da dinâmica de geração, manutenção ou transformação dos padrões concorrenciais e, por extensão, da competitividade setorial.

\section{Competitividade Sob Forma de Padróes Institucionais}

Apesar da argumentação em contrário, a procura por novas explicações para o fenômeno da competitividade no campo das ciências econômicas parece ainda nortear-se pela lógica da eficiência. Em consonância com o clássico esquema de escolha racional, o pesquisador infere que as organizações estão situadas em mercados atomizados, caracterizados como a fonte reguladora primordial das informações e recursos requeridos por seus sistemas produtivos. No âmbito da teoria das organizações, enfoques de inspiração sociológica tentam explorar a questão sob outro prisma, ao atentarem para o efeito das fontes exógenas de legitimidade e interpretação. Dentre eles, se destaca a abordagem institucional.

De acordo com os institucionalistas, as organizações estão inseridas em um ambiente constituído por regras, crenças e valores, criados e consolidados por meio da interação social. Nesse sentido, a sua sobrevivência depende da capacidade de atendimento à orientações coletivamente compartilhadas, cuja permanente sustentação contribui para o êxito das estratégias implementadas e, por conseguinte, para o pleno funcionamento interno. Assim, diante das mesmas prescrições ambientais, as organizações também competem pelo alcance da legitimidade institucional, o que torna suas práticas cada vez mais homogêneas, ou isomórficas (Meyer \& Rowan, 1992; Scott, 1987, 1992). 
DiMaggio e Powell (1983) sugerem que o isomorfismo decorre da interferência de três mecanismos básicos. Em primeiro lugar, as expectativas culturais propagadas pela sociedade, e as pressões formais e informais exercidas pelo Estado ou pela indústria, por exemplo, obrigam as organizações a adotarem estratégias similares, culminando em um isomorfismo coercitivo. Por outro lado, os dirigentes tendem a imitar procedimentos implantados pelos concorrentes, em busca do sucesso por eles conquistado no manejo das incertezas geradas pelas exigências ambientais, o que caracteriza um isomorfismo mimético. Não obstante, a progressiva especialização profissional dos membros de uma determinada ocupação, favorece a criação e a posterior disseminação de normas de atuação, ou o isomorfismo normativo. A combinação desses mecanismos de natureza coercitiva, mimética e normativa acarreta a construção de uma ordem institucional, que regula qualquer tentativa de manipulação da organização das circunstâncias ambientais no transcorrer do tempo (Meyer \& Rowan, 1992).

Todavia, a tendência à homogeneização não anula as demandas competitivas, conforme grande parte das pesquisas empíricas efetuadas com base nesta perspectiva parece sugerir. Em termos analíticos, "processos competitivos e institucionais não são necessariamente opostos" (Powell, 1991, p. 183). No âmago de tal questão conceitual, encontra-se a distinção inicial entre ambiente técnico e ambiente institucional.

Os ambientes técnicos, ou espaços de competição na ótica econômica, são aqueles cuja dinâmica de funcionamento desencadeia-se por meio da troca de bens ou serviços, de modo que as organizações que neles se incluem são avaliadas pelo processamento tecnicamente eficiente do trabalho. Logo, o controle ambiental é exercido sobre os resultados em termos de quantidade e qualidade, modelando as organizações através de um isomorfismo competitivo. Indústrias sujeitas a uma economia de mercado exemplificariam a força dos fatores técnicos (DiMaggio \& Powell, 1983; Scott \& Meyer, 1992).

Os ambientes institucionais caracterizam-se, por sua vez, pela elaboração e difusão de regras e procedimentos, que proporcionam às organizações legitimidade e suporte contextual. Nesse caso, o controle ambiental incide sobre a adequação da forma organizacional às pressões sociais, resultando em um isomorfismo institucional. Conforme mencionado anteriormente, sob condições de incerteza, as organizações sujeitam-se a requerimentos governamentais, copiam estruturas e práticas, ou implementam medidas genericamente aceitas em redes profissionais. Igrejas, escolas e hospitais públicos constituiriam alguns exemplos da influência dos fatores institucionais (DiMaggio \& Powell, 1983; Scott \& Meyer, 1992).

Por concentrarem-se no exame de organizações não-lucrativas, a maioria dos estudiosos tende a elaborar as suas investigações a partir da diferenciação entre 
ambiente técnico e ambiente institucional. Entretanto, Powell (1991) afirma que, de fato, uma confusão entre formulação analítica e problema empírico parece estar se instaurando. Assim, tratar as distinções propostas enquanto facetas de uma mesma dimensão, talvez se revele como uma alternativa mais promissora. Afinal, alguns setores como o bancário sofrem pressões de caráter técnico e institucional de igual intensidade, como observam Scott e Meyer (1992). Em outras palavras, urge assumir que a ocorrência de um conjunto de condições não exclui a presença do outro. Apenas supõe que o processo de institucionalização restringe-se a uma questão de grau, já que a fundação e a evolução dos campos organizacionais variam de acordo com circunstâncias históricas e temporais (Powell, 1991).

Além disso, aplicações bem sucedidas dos pressupostos da abordagem institucional no setor privado, como o estudo pioneiro de Fligstein (1985) acerca das causas da diversificação das grandes corporações americanas, também ilustram as possibilidades de interseção. Destacam-se ainda na literatura especializada, algumas recentes tentativas em contemplar a dinâmica de convergência entre fatores técnicos e institucionais em um mesmo campo organizacional, como a pesquisa realizada por Orrù, Biggart e Hamilton (1991) na Ásia Oriental.

Ao analisarem agrupamentos de organizações dominantes do setor privado localizadas no Japão, na Coréia do Sul e em Taiwan, Orrù et al. (1991) verificaram a existência de distintos padrões em termos de gestão, produção, finanças e modos de propriedade. Mas em cada sociedade os princípios fundamentais de controle são extraídos de fontes institucionais como o Estado, a comunidade ou a família, motivando a formação de interações previsíveis em múltiplos contextos, como o fiscal, o econômico, o político e o cultural. Assim, a influência de agrupamentos sociais diversificados, em especial do Estado, nas relações intra e interorganizacionais, indica que são os fatores institucionais coercitivos que possibilitam a viabilidade das organizações nestes países.

No Japão, por exemplo, as organizações possuem um ideal comunitário. Como em outros tipos de agrupamento social, mantêm uma relação de status bem definida, mas as decisões são tomadas em grupos, de acordo com consenso, e contemplam o bem-estar da coletividade. Na Coréia do Sul emerge o princípio patrimonial. As organizações são dominadas pelo patriarca e seus filhos, que desempenham um comando centralizado e apoiado pelo Estado, ainda que não ocupem cargos diretivos. Em Taiwan a família também exerce uma forte influência na direção dos negócios, mas seus membros assumem vários cargos executivos, a fim de reforçar a sua autoridade e assegurar o alcance dos seus interesses. E, sobretudo, as mesmas normas que regem o funcionamento das organizações 
inseridas em cada uma destas sociedades, derivadas de concepções amplamente aceitas sobre o papel do Estado, da comunidade ou da família na condução da atividade industrial, se expressam na interação entre elas.

Portanto, à semelhança do que ocorre nos países ocidentais, preceitos capitalistas baseados em noções de lucratividade e competição também regulam a dinâmica de mercado na Ásia Oriental. No entanto, a ação organizacional é desencadeada a partir do reconhecimento de que vantagens competitivas são obtidas mediante a implantação de estratégias coerentes com o conjunto de significados socialmente compartilhado. Especificamente, princípios institucionais condicionam a construção de uma lógica de atuação competitiva, resultando em modelos de comportamento que direcionam as relações entre as organizações, e as induzem a se confrontarem de uma maneira homogênea (Orrù et al., 1991).

Segundo DiMaggio e Powell (1991), este estudo demonstra que mais do que negar a importância da competitividade, os institucionalistas atualmente enfatizam a variabilidade histórica e intersocial de nichos de mercado, e o papel das instituições na sua construção. Nesse sentido, os fatores institucionais convergem com os fatores técnicos no estabelecimento das formas e das relações organizacionais, à medida que favorecem a legitimação das ações. Como sugerem Orrù et al. (1991, p. 363), "as pressões institucionais podem contribuir para a emergência e a manutenção de uma ordem de mercado tanto dentro como entre organizações competitivas".

\section{Conciliação entre Padrões Concorrencials e Padróes INSTITUCIONAIS}

O quadro acima esboçado revela que, quando o assunto é competitividade, a abordagem econômica direciona a atenção do investigador para a identificação dos fatores que possibilitam à organização, sob condições de competição perfeita, cumprir concomitantemente as especificações do mercado e do seu sistema produtivo. Acredita-se que, nos dias atuais, além da inexistência real de semelhante situação, tal procedimento permite que se continue a negligenciar um pressuposto weberiano elementar: a legitimação ambiental das ações organizacionais. Isso pressupõe, segundo DiMaggio e Powell (1991), transferir o foco de análise do discernimento da eficiência ou não de estruturas e processos internos para a incorporação dos significados externos aos princípios de conduta organizacional. Conforme salientado, a abordagem institucional assume essa preocupação, fundamentando-se no pressuposto básico de isomorfismo ambiental. Com vistas a uma conciliação, alguns pontos merecem, no entanto, ser esclarecidos. 
Entende-se por institucionalização, o processo de transformar crenças e ações em regras de conduta social. Ao longo do tempo, por influência de mecanismos de aceitação e reprodução, tais regras tornam-se padrões, e passam a ser visualizadas como rotinas naturais, ou concepções amplamente compartilhadas da realidade (Berger \& Luckmann, 1967; Jepperson, 1991; Meyer \& Rowan, 1992). Desse modo, embora a legitimidade se instale sem a clara intervenção de escolhas racionais, processos de 'desinstitucionalização' podem ocorrer, em função de questionamentos internos a respeito da adequação de práticas e procedimentos às exigências ambientais. $\mathrm{O}$ colapso resultante expõe a organização a um estado de vulnerabilidade, criando um vácuo institucional, passível de ser preenchido somente por meio da re-definição e posterior re-legitimação de novas concepções e operações, o que caracteriza um processo de 'reinstitucionalização' (Clark \& Soulsby, 1995; Jepperson, 1991).

A cadeia descrita sugere, dentre outros aspectos, que tais processos devem ser compreendidos como propriedades do nível macro de relação entre organização e ambiente, mas com efeitos recíprocos no nível micro de conduta organizacional. Assim, ao contrário do enfoque econômico, o raciocínio subjacente ao desenvolvimento do enfoque institucional orienta-se no sentido de fora para dentro. Em outras palavras, diante da necessidade de elaboração de uma resposta às pressões contextuais, enquanto a adoção da primeira abordagem conduz à tendência em concentrar-se na avaliação das limitações técnicas da organização a partir da comparação com os resultados alcançados pelos concorrentes, a segunda salienta a importância em buscar-se a conformidade à padrões normativos de suporte e legitimação, com base na sua interpretação. Nesse caso, a definição de estratégias de ação é predominantemente orientada pelo uso de esquemas interpretativos, enquanto representações cognitivas que condicionam a leitura interna e a consequente aceitação externa. Ou seja, as pessoas percebem, identificam e interpretam os componentes da sua realidade. Esse conjunto de interpretações é mentalmente elaborado e arquivado em esquemas interpretativos, cujos elementos constitutivos vão permitir a compreensão dos significados das prescrições ambientais (Bartunek, 1984; Machado-da-Silva \& Fonseca, 1995; Ranson, Hinings, \& Greenwood, 1980).

Clark e Soulsby (1995) procuram elucidar essa dinâmica de interação entre transformação institucional e ajustamento organizacional em uma pesquisa realizada na República Tcheca. Os autores argumentam que a transição de uma economia centralizada para uma economia de livre mercado, vislumbrada como prioritária após a mudança política ocorrida nos países do Leste Europeu ao final da década de oitenta, suscitou um impasse acerca da estruturação das organizações públicas aí localizadas, cuja resolução independe da exclusiva alteração no modo de propriedade. Partindo da análise de três empresas estatais 
tchecas do setor metal-mecânico, eles observaram, por exemplo, que as medidas implantadas como parte do início do processo de privatização, refletiram a ambivalência experimentada pelos administradores diante das circunstâncias então emergentes. As agências centrais de planejamento se dissiparam imediatamente, e o mercado consumidor, formado em sua maioria pelos integrantes do Bloco Soviético, tornou-se anárquico. Mas diversos membros do Partido Comunista assumiram cargos de direção, despertando a indignação dos empregados. Além disso, a forma organizacional dominante, compatível com a rigidez e a relativa estabilidade propiciada pelo antigo regime, perdeu a coerência mediante a propagação de concepções de cunho capitalista, convertendo-se em alvo de ataques populares.

Neste contexto, as mudanças promovidas nas organizações focalizadas resumiram-se à instalação de tecnologias de informação e métodos de controle da produção mais atualizados, e à implantação de uma estrutura multidivisional. Em termos técnicos, a opção por tal tipo de estrutura indicou a existência de um elevado grau de isomorfismo mimético, já que foi adotado um procedimento comumente utilizado e recomendado no Ocidente para a reordenação do arranjo formal. Todavia, no cotidiano ela assumiu uma importância simbólica, ao guiarse pela necessidade dos diretores de demonstrar aos clientes, fornecedores e empregados a seriedade de seus esforços para o êxito na participação em uma economia de mercado. Assim, o anseio por credibilidade da parte dos dirigentes sobrepujou a busca pela legitimidade ambiental das organizações, prejudicando o pleno alcance dos resultados esperados com a mudança. Embora apreciando algumas consequências da descentralização, tais como o trabalho em equipe, os ocupantes dos cargos de nível médio continuaram a tomar decisões de acordo com a hierarquia, por sentirem-se incapazes de arcar com as novas responsabilidades e obrigações. Em decorrência, uma intensa resistência se manifestou, demonstrando que suas experiências e expectativas ainda se norteavam pelos esquemas interpretativos consolidados durante a vigência do regime anterior. Portanto, a transformação geral requerida para as organizações tchecas foi limitada pela ausência de reciprocidade entre exigências ambientais, alterações estruturais e adaptação de valores organizacionais, característica do processo de 'desinstitucionalização' (Clark \& Soulsby, 1995).

A conclusão deste estudo permite captar o aspecto cognitivo da legitimidade, pouco enfatizado na literatura especializada. Como afirmam Wuthrow et al. (como citado em Scott, 1991, p. 169), mais do que a adequação de concepções organizacionais, em sua correta acepção o conceito envolve o problema de "explicar ou justificar a ordem social de modo a tornar os arranjos institucionais subjetivamente plausíveis". Em particular, de reconhecer que os indivíduos interpretam e definem ações conforme os significados que atribuem a realidade 
na qual se encontram inseridos. Logo, qualquer transformação ambiental revestese, simultaneamente, de um caráter simbólico e material, cujo efeito sobre a organização depende da configuração de sua lógica interna, ou da combinação de seus elementos culturais em um dado momento do tempo (Friedland \& Alford, 1991). Por conseguinte, embora convergindo para a homogeneização de procedimentos e operações, a força das pressões isomórficas é experimentada em diferentes graus, suscitando diversas respostas organizacionais (Powell, 1991).

Em um estudo recentemente efetuado no pólo calçadista de Novo Hamburgo, no Estado do Rio Grande do Sul, foi possível visualizar tal inclinação, ao verificar-se que algumas organizações com arranjos estruturais equivalentes, situadas em uma mesma fase de desenvolvimento, adotavam posturas estratégicas diferentes (Machado-da-Silva \& Fonseca, 1995). A análise realizada mostrou que as pressões governamentais rumo à modernização da indústria brasileira, intensificadas a partir do começo dos anos noventa por meio do lançamento de programas como o de qualidade e produtividade, não afetaram a forma organizacional dos componentes da população pesquisada. Tampouco detectou-se a ocorrência de uma influência modeladora de caráter mimético, previsível perante a implantação de tecnologias inovadoras pelas organizações nacionais de maior destaque no setor. A esse respeito, reações à exigências de inovação e maior produtividade apresentaram-se apenas como um reflexo direto do comportamento manifesto pelos concorrentes mais próximos em função de flutuações ambientais, conduzindo à imitação de instrumentos para a manutenção do sistema produtivo e não de escolhas estratégicas. Concluiuse, assim, que o isomorfismo mimético orientou implicitamente as ações no interior do nicho populacional. Exigências institucionais de fora para dentro tomaram-se neutralizadas.

Reportando-se à temática em questão, sob a ótica da abordagem econômica os resultados desta pesquisa apontam para a conformidade à situação concorrencial existente na indústria específica. Afinal, seus argumentos fundamentam-se no princípio de que as organizações produzem bens e serviços a serem trocados em um mercado que as recompensa pelo controle eficiente do processo de trabalho. A despeito da exatidão de tal avaliação, as dificuldades ora enfrentadas pelo setor industrial anteriormente mencionado comprovam a sua limitação. Com base nos pressupostos da abordagem institucional, pode-se afirmar que mesmo a criação, a consolidação e a alteração do padrão de concorrência vigente em um determinado setor, configuram-se por elementos que transcendem a mera consideração dos aspectos de eficiência técnica ou de desempenho, tais como as crenças e os valores sociais. Em termos da conciliação proposta, inferese que uma explicação mais completa talvez se encontre na probabilidade das organizações geraram versões múltiplas e diversificadas de um mesmo padrão institucional, de acordo com os ditames de sua lógica interior, conforme salientado, 
e com a capacidade de amenizar o impacto das exigências advindas do contexto externo em favor da manutenção de vantagens competitivas obtidas a nível local e, por extensão, da sua legitimação. Isso sugere que o conjunto de significados internamente consolidado também rege a escolha da esfera de atuação sobre a qual a organização pretende operar.

É pertinente ressaltar que, nesse âmbito, Scott (1992) distingue o campo interorganizacional, o campo social e o campo mundial enquanto níveis de análise. Devido à expansão atual dos tipos de transações entre organizações, acredita-se que uma classificação mais precisa deve abarcar os níveis local, regional, nacional e internacional. Considerando-se a questão da globalização, por exemplo, a reunião das idéias precedentes sugere que, na verdade, a organização mais competitiva é aquela que absorve as concepções subjacentes à sustentação do padrão de concorrência internacional, e as aplica na definição de estratégias coerentes de ação. Sob esse prisma, a competitividade vincula-se a crenças e valores externamente aceitos e compartilhados, interpretados de acordo com o quadro de referência cultural e relacional da organização.

\section{Considerações Finais}

Decorridos cerca de dez anos do fim do período de transição para o estabelecimento do regime democrático, o Brasil parece ainda encontrar dificuldades para solucionar antigos problemas conjunturais. Os fracassos acumulados pelos frequentes planos de estabilização econômica, instaurados na tentativa de atingir patamares anteriores de crescimento, terminaram por imprimir um ritmo descontínuo aos processos de investimento e de produção, acarretando a estagnação das atividades industriais e, sobretudo, o distanciamento dos fluxos do comércio internacional. Diante desse contexto, a recente promulgação de uma Política de abertura de mercados exigiu das organizações a revisão das formas de condução e de operacionalização do trabalho, lançando-as à exaustiva busca por concepções passíveis de proporcionar a modernização necessária, para a sua sobrevivência em um cenário de competição.

Os questionamentos existentes na literatura especializada sugerem que os modelos teóricos vigentes, em especial aqueles desenvolvidos no campo da microeconomia, têm-se revelado insuficientes para suprir tal busca. Nesse sentido, a conciliação entre abordagens oriundas de diferentes áreas do conhecimento talvez contribua para um melhor entendimento da dinâmica de construção da competitividade, e ofereça, assim, uma resposta mais satisfatória aos anseios das organizações. 
No conjunto das abordagens de cunho sociológico, considera-se a teoria institucional como aquela capaz de fornecer uma nova perspectiva à temática em questão, ao sustentar que a conduta organizacional também é modelada por elementos sócio-culturais, e não somente por fatores técnicos e financeiros, internos ou externos. Como afirma Scott (1992. p. 160), na atualidade as organizações "não existem e competem como unidades individuais autônomas, mas como membros de amplos sistemas". Logo, até o mercado deixa de configurar-se como um simples espaço de alocação, e conforma-se como um sistema social coletivamente concebido para gerar legitimação (Friedland \& Alford, 1991).

Entretanto, convém salientar que devido ao reduzido tempo de utilização para o estudo das organizações, a abordagem institucional ainda incorre em algumas limitações. Dentre elas, se destaca a carência de pesquisas que testem os seus pressupostos básicos, com vistas à adequada aplicação para a explicação de fenômenos que, a princípio, se encontram a margem do seu foco de análise, como é o caso da competição. A exposição acima efetuada ilustra essa evidência. Sob tal aspecto, a discussão aqui iniciada torna-se igualmente suscetível a testes empíricos, que permitam comprovar a validade das proposições apresentadas e, por conseguinte, orientar a formulação de futuras investigações, com vistas a uma complementação.

\section{RefERÊNCIAS BibliográficAs}

Bartunek, J. M. (1984).

Changing interpretive schemes and organizational restructuring: the example of a religious order. Administrative Science Quarterly, 29(3), 355-372.

Berger, P. L., \&

Luckmann, T. (1967).

The social construction of reality. New York: Doubleday.

Clark, E., \&

Soulsby, A. (1995).

Transforming former state enterprises in the Czech Republic. Organization Studies, 16(2), 215-242.
Correa, P. G., \&

Kupfer, D. (1991).

Padrão de concorrência e dinâmica competitiva: o caso da indústria brasileira de máquinas-ferramenta [Texto para discussão]. Rio de Janeiro: UFRJ/IEI.

DiMaggio, P. J., \&

Powell, W. W. (1983).

The iron cage revisited: institutional isomorphism and collective rationality in organizational fields. American Sociological Review, 48(2), 147-169. 
DiMaggio, P. J., \&

Powell, W. W. (1991).

Indroduction. In W. W. Powell \& P. J. DiMaggio (Eds.), The new institutionalism in organizational analysis (pp. 1-38). Chicago: The University of Chicago Press.

Fligstein, N. (1985).

The spread of the multidivisional form among large firms, 1919-1979. American Sociological Review, 50(3), 377-391.

Friedland, R., \&

Alford, R. R. (1991).

Bringing society back in: symbols, practices, and institutional contradictions. In W. W. Powell \& P. J. DiMaggio (Eds.), The new institutionalism in organizational analysis (pp. 232-263). Chicago: The University of Chicago Press.

Haguenauer, L. (1983).

Competitividade: conceitos e medidas [Texto para discussão]. Rio de Janeiro: UFRJ/IEI.

Hannan, M. T., \&

Freeman, J. (1977).

The population ecology of organizations. American Journal of Sociology, 82(5), 929-964.

Hannan, M. T., \&

Freeman, J. (1989).

Organizational ecology. Cambridge: Harvard University Press.

Jepperson, R. L. (1991).

Institutions, institutional effects, and institutionalism. In W. W. Powell \& P.
J. DiMaggio (Eds.), The new institutionalism in organizational analysis (pp. 143-163). Chicago: The University of Chicago Press.

Kupfer, D. (1991).

Padrões de concorrência e competitividade [Texto para discussão]. Rio de Janeiro: UFRJ/IEI.

Machado-da-Silva, C. L., \&

Fonseca, V. S. da (1995).

Configuração estrutural da indústria calçadista de Novo Hamburgo. In J. E. Fensterseifer (Org.), O complexo calçadista em perspectiva: tecnologia e competitividade (pp. 217-245). Porto Alegre: Ortiz.

Meyer, J. W., \&

Rowan, B. (1992).

Institutionalized organizations: formal structure as myth and ceremony. In J. W. Meyer \& W. R. Scott (Eds.), Organizational environments: ritual and rationality. London: Sage Publications.

Nascimento, A., Neto (1996, abril 3).

A roda global: o que é a globalização, que provoca tanto medo, e o que se pode esperar dela. Revista Veja, (14), Ano 29, 80-89.

Orrù, M.,

Biggart, N. W., \&

Hamilton, G. G. (1991).

Organizational isomorphism in East Asia. In W. W. Powell \& P. J. DiMaggio (Eds.), The new institutionalism in organizational analysis (pp. 361-389). Chicago: The University of Chicago Press. 
Powell, W. W. (1991).

Expanding the scope of institutional analysis. In W. W. Powell \& P. J. DiMaggio (Eds.), The new institutionalism in organizational analysis (pp. 183-203). Chicago: The University of Chicago Press.

Ranson, S.,

Hinings, B., \&

Greenwood, R. (1980).

The structuring of organizational structures. Administrative Science Quarterly, 25(1), 1-17.

Scott, W. R. (1987).

The adolescence of institutional theory. Administrative Science Quarterly, 32(4), 493-511.

Scott, W. R. (1991).

Unpacking institutional arguments. In W. W. Powell \& P. J. DiMaggio (Eds.), The new institutionalism in organizational analysis (pp. 164182). Chicago: The University of Chicago Press.

Scott, W. R. (1992).

The organization of environments: network, cultural, and historical elements. In J. W. Meyer \& W. R. Scott (Eds.), Organizational environments: ritual and rationality. London: Sage Publications.

Scott, W. R., \&

Meyer, J. W. (1992).

The organization of societal sectors. In J. W. Meyer \& W. R. Scott (Eds.), Organizational environments: ritual and ationality. London: Sage Publications.

Senge, P. M. (1990).

A quinta disciplina: arte, teoria e prática da organização de aprendizagem (10a ed.). São Paulo: Best Seller. 